\title{
0 direito à informação: os arquivos da "guerra suja" na América Latina
}

\section{Samantha Viz Quadrat}

CATELA, Ludmila da Silva y JELIN, Elizabeth (comps.). Los archivos de la represión: documentos, memoria y verdad. Buenos Aires: Siglo XXI, 2002. Vol. 4 - Série Memoria de la represión.

Em outubro de 2004, o jornal Correio Brasiliense publicou uma série de supostas fotos do jornalista Vladimir Herzog, ainda vivo, na prisão. As fotos causaram um forte impacto e comoção na sociedade. Além disso, trouxeram para o espaço público uma discussão que tendia a ficar restrita aos meios acadêmicos e aos atingidos diretamente pela repressão militar, a saber: o Decreto no 4.553, de 27 de dezembro de 2002, que dificultou o acesso aos arquivos da ditadura militar. Ainda que as Forças Armadas neguem a existência de qualquer arquivo dessa época, a divulgação de fotos, como as publicadas pelo Correio Brasiliense, ou de documentos sigilosos, recorrentemente apresentados em diversos meios de comunicação nacionais, demonstram justamente o contrário: arquivos foram criados, afinal, eram órgãos de repressão, mas também de inteligência.

$\mathrm{O}$ acesso à informação é um tema que tem gerado muitas discussões nos países latino-americanos que estiveram sob alguma forma de ditadura durante a segunda metade do século XX. A busca e a conseqüente abertura de arquivos da chamada "guerra suja", ou seja, sobre os crimes de violações aos direitos humanos, tem motivado pesquisadores, membros do poder judiciário e organizações de direitos humanos. No rastro desse debate o quarto volume da Série Memorias de la represión busca discutir os aspectos relacionados a esses arquivos tendo como elo de ligação os temas da verdade, justiça e memória.

A série traz a público os resultados do Programa "Collective Memory of Repression in the Southern Cone and Peru", sob a coordenação dos 
professores Elizabeth Jelin (Argentina) e Carlos Iván Degregori (Peru). Desenvolvido dentro do âmbito do Social Science Research Council, sob o financiamento das Fundações Ford, Rockefeller e Hewlett, o programa durou três anos e contou com a participação de mais de 50 jovens pesquisadores dos países do Cone Sul, do Peru e também dos Estados Unidos. Para cada ano houve um tema central. Dessa maneira, no primeiro ano as discussóes giraram em torno de "datas" e "lugares", no segundo ano privilegiou-se atores e instituições e no terceiro ano ampliou-se a temática anterior incorporando a questão dos jovens diante do passado recente de seu país.

Como afirma o texto de apresentação, publicado em todos os volumes, o programa foi pensado para discutir três questôes: a necessidade de promover avanços teóricos e metodológicos, a promoção de uma nova geração de pesquisadores e a formação de uma rede de intelectuais que possam trocar experiências e integrar as ciências humanas na região. Além disso, uma outra contribuição do programa foi a organização, em parceria com a Facultad de Filosofía y Letras da Universidad de Buenos Aires, de uma biblioteca voltada para a questão da memória e da violência políticas.
O quarto volume, à semelhança dos anteriores, apresenta artigos dedicados aos países do Cone Sul. Contudo, desde logo é necessário observar a ausência de artigos voltados para o Peru e o Uruguai, integrantes do programa que não foram contemplados nesse volume, gerando a dúvida sobre a existência ou não de arquivos da repressão nesses países. A maior parte dos textos resulta das pesquisas dos bolsistas. Apenas três foram escritos em função de uma solicitação das organizadoras com o intuito de suprir as lacunas por elas identificadas.

A introdução intitulada "Gestión política, gestión administrativa y gestión histórica, ocultamiento y descubrimientos de los archivos de la repressión", escrita pela coordenadora do projeto, Elizabeth Jelin, ultrapassa os limites tradicionais de apresentação dos artigos ao levantar questôes sobre a existência de arquivos, seu significado, o que deve ser ou não guardado e a importância que esses arquivos adquirem na medida em que se transformam também em provas judiciais da violência do Estado. Um outro aspecto relevante diz respeito ao binômio público e privado. Afinal, muitos documentos que hoje integram o acervo destes arquivos são pessoais, 
como cartas e álbuns de fotografias, o que desperta o desejo de tê-los de volta ou de não querer ter exposta aos olhos do público uma parte da sua vida privada.

Ainda sobre os aspectos gerais dos arquivos encontramos o texto da outra organizadora, Ludmila da Silva Catela, mestre e doutora em Antropologia Cultural pela UFRJ. O seu artigo de encerramento, "El mundo de los archivos", resgata a tradição francesa ao discutir os arquivos como parte importante da identidade nacional. Um outro aspecto importante discutido por Catela é a reconstrução da memória. Nesse sentido, se os arquivos servem como fontes para trabalhos de pesquisadores e provas para a justiça, eles também permitem que as vítimas da repressão legitimem o seu testemunho, são "provas" até então ocultas de seu sofrimento. Para algumas vítimas da repressão a sociedade não acredita em seu testemunho ou, ainda que acredite, elas, as vítimas, sentem-se aliviadas em poderem "provar", especialmente com documentos oficiais, a tortura sofrida na clandestinidade.

Catela reforça que existem quatro elementos centrais sobre os arquivos da repressão e que devem ser caros não apenas aos especialistas, mas também à sociedade. $\mathrm{O}$ primeiro, os documentos atualmente servem para as vítimas buscarem alguma forma de compensação e também reconstruírem aquele momento da sua vida. O segundo, servem de provas para acabar com a impunidade aos militares envolvidos com a repressão. Terceiro, servem aos pesquisadores como fontes. E, quarto, servem também como liçōes pedagógicas sobre o passado de intolerância e violência. Ainda que esse último ponto seja pouco discutido no Brasil, há um certo consenso entre os países do Cone Sul que a história das últimas ditaduras militares requer tratamento especial nas escolas e nas universidades para que a expressão nunca mais de fato se concretize como uma perspectiva social.

Sobre os demais artigos que compõem a coletânea podemos afirmar que eles estão divididos de acordo com os dois tipos de arquivos que encontramos das ditaduras militares: os arquivos compostos pelos documentos produzidos pela repressão e os arquivos das organizaçóes de direitos humanos sobre a repressão. Ainda que exista essa diferença, os artigos acabam por apresentar pontos comuns, tais como: a identificação da formação do acervo, sua des- 
coberta ou divulgação; o debate sobre as leis ou normas de acesso; a disputa pelo acervo e uma visão geral de como cada ditadura lidou com a documentação por ela produzida.

No primeiro tipo de arquivo, ou seja, os produzidos pela repressão, encontramos os artigos sobre o Brasil e Paraguai. Os dois países são considerados uma exceção no Cone Sul pela existência de arquivos policiais, civis ou militares sobre a ditadura militar que podem ser consultados.

Sobre o Brasil encontramos a segunda contribuição de Ludmila Catela com o artigo intitulado "Territorios de memoria política. Los archivos de la represión en Brasil". Bolsista do projeto, Catela estudou os arquivos do DOPS do Rio de Janeiro, a polícia política do estado, e do Projeto Brasil: Nunca Mais, composto pelas fotocópias dos processos do Superior Tribunal Militar roubadas ainda durante a ditadura.

$\mathrm{O}$ artigo, a maior de todas as contribuições do livro, pode ser dividido em duas partes. A primeira, na qual a autora se preocupa em descrever os dois acervos pesquisados. E, a segunda, na qual descreve os movimentos em torno dos arquivos. É interessante notar como a história desses acervos é desconhecida, especialmente a trajetória do
Projeto Brasil: Nunca Mais, descrita em seus pequenos detalhes. É emocionante e, apesar de já sabermos o "final da história", faz com que o leitor se envolva e compartilhe com a equipe o medo, a ansiedade, a cumplicidade e vontade de que "tudo dê certo". Apropriadamente chamado por Catela de a "verdade roubada", a compilação dos dados dos processos, momento em que presos aproveitavam a ocasião para denunciar a tortura, originou o livro Brasil: Nunca Mais. Publicado em 1985, o livro é até hoje um dos maiores sucessos editoriais brasileiro.

Sobre o DOPS-RJ, Catela recupera a trajetória do órgão e também a história de seu arquivo desde a descoberta dos documentos até os dias de hoje, onde ganham destaque as leis de acesso à documentação e a disputa pelo prédio na Rua da Relação. O local é a antiga sede do órgão, o que gera a dimensão simbólica do retorno dos arquivos. Além disso, a própria situação física em que se encontra o arquivo, sempre localizado em prédios precários, como o atual na Praia de Botafogo, torna necessária a mudança.

O Paraguai é brindado com o artigo "Los Archivos del terror del Paraguay. La historia oculta de la 
represión de Myrian Gonzáles”. O arquivo paraguaio, também conhecido como do Horror ou do Terror, talvez seja o melhor exemplo de como esses arquivos adquiriram diante dos processos internacionais uma nova dimensão. Atualmente o arquivo, descoberto após uma denúncia anônima, é um dos principais fornecedores de "provas" para os processos judiciais na América Latina e na Europa.

Através de entrevistas, González reconstrói a descoberta do acervo em 1992, na cidade de Lambaré, próxima à capital Assunção, e a maneira como a população tomou "posse" da documentação. Vigiando, protegendo, cuidando para que nenhum retrocesso ocorresse com a descoberta. No entanto, tanto cuidado não impediu que alguns itens, como objetos, fotos e fichas, fossem retirados por seus antigos proprietários. O que nos remete ao tema das disputas entre o que seria público, por estar na posse do Estado, ou privado, por ter sido roubado pelas forças de repressão.

Um outro ponto que González consegue alcançar diz respeito ao impacto que a descoberta da violência da ditadura stronista teve não só em todo o Paraguai, mas também na comunidade internacional. Organi- zaçôes de direitos humanos, familiares e vítimas recorreram ao acervo paraguaio, onde é comum encontrarmos documentação das demais ditaduras, como cartas, palestras, troca de informações e até mesmo fichas de militantes brasileiros.

Sobre o arquivo paraguaio é importante ainda ressaltar que foi perdido em meio a milhares de documentos, acompanhamento quase diários dos considerados "inimigos", objetos pessoais, fotografias de famílias e também de mortos - que se encontrou o convite para a Operação Condor, a colaboração oficial entre as ditaduras do Cone Sul.

Por fim, no que tange aos arquivos produzidos pela repressão, ainda que de uma perspectiva distinta, temos a contribuição de Darío Olmo, que assinou o artigo "Reconstruir desde restos y fragmentos. El uso de archivos policiales en la antropologia forense en Argentina”. Darío foi convocado para integrar a coletânea em função da sua experiência à frente da chefia da pioneira Equipe de Antropologia Forense Argentina, especialista em localizar e identificar corpos das vítimas da repressão das ditaduras latino-americanas.

$\mathrm{O}$ artigo de $\mathrm{Olmo}$ adquire uma dimensão especial, visto que a Argentina se encontra numa situação 
bastante delicada no que diz respeito à questão dos arquivos, já que os militares antes de deixarem o poder assinaram o Decreto no 2.726/83, que instruía incineração de qualquer documento da "guerra suja". Desde então, pesquisadores, membros do Poder Judiciário, organizaçōes de direitos humanos, vítimas e familiares buscam qualquer fragmento oficial da repressão.

$\mathrm{Na}$ descrição do trabalho da Equipe de Antropologia Forense, Olmo aponta como inicialmente cotejavam os dados sobre os desaparecimentos na documentação da Comissão Nacional sobre o Desaparecimento de Pessoas (CONADEP), na Câmara Federal, na imprensa, nos acervos das organizações de direitos humanos e na própria metodologia da Equipe. Contudo, a partir de 1996, a Equipe teve acesso a uma preciosidade até então clandestina, o arquivo da Direção de Inteligência da Polícia da Província de Buenos Aires, que permitiu até o presente momento a identificação de dezenas de desaparecidos.

A pesquisa de Olmo demonstra a necessidade de reunir dados, confrontar informaçóes e o esforço da Equipe Forense em decifrar o quebra-cabeças dos 30.000 mortos e desaparecidos da ditadura militar argentina.
Como destacamos no início dessa resenha, existem também os acervos sobre a repressão normalmente produzidos pelas organizaçôes de direitos humanos. Nesse aspecto, a coletânea destaca os casos do Brasil e do Chile.

A emoção não escapou a Samarone Lima no artigo "Clamor: la colcha de retazos de la memoria". Lima é um dos poucos especialistas sobre o Clamor, grupo criado em 1978 com três objetivos: dar assistência aos refugiados, divulgar as denúncias do uso da violência por parte do Estado e estabelecer contatos com outras organizaçóes visando a defesa dos direitos humanos. Para isso, o grupo só existiria enquanto houvesse alguma ditadura na região.

O grupo era formado basicamente por D. Paulo Evaristo Arns, Jaime Wright (lideres do Projeto Brasil: Nunca Mais), a jornalista Jan Rocha e o advogado Luis Eduardo Greenhalgh.

Mais do que a história do grupo, o artigo conta a saga pessoal de Lima para ter acesso aos seus arquivos. Misterioso, como sua atuação necessitava na época, assim o grupo permaneceu em tempos democráticos, demonstrando que nem sempre o acesso à documentação é difícil apenas nos arquivos oficiais da repressão. 
A respeito do Chile existe o trabalho "Silencios, contigencias y desafios: el Archivo de la Vicaría de la Solidaridad en Chile", escrito por Maria Angélica Cruz.

A Vicaría de la Solidaridad foi criada pela Igreja Católica no início da ditadura do general Augusto Pinochet, em 1973, com o intuito de promover e defender os direitos humanos no Chile. Um dos primeiros organismos de resistência à ditadura pinochetista, a Vicaría conseguiu reunir ao longo da sua existência (1973-1990) cerca de 45.000 fichas, que hoje formam, juntamente com outros documentos, o acervo da Fundação de Documentação e Arquivo da Vicaría de la Solidaridad, onde encontram-se as trajetórias de chilenos e estrangeiros vítimas da repressão.

Além de discutir pontos caros aos demais artigos, como a disputa pela documentação, o seu uso como "comprovação da verdade" e da justiça ao contradizer informaçōes fornecidas pelo governo, Cruz discute um outro aspecto que foi apresentado no decorrer da coletânea de maneira discreta. Estamos falando da visibilidade que a documentação sobre as ditaduras adquirem de tempos em tempos. Dessa maneira, Cruz quis chamar atenção para as dinâmi- cas da memória coletiva que em alguns momentos colocam o tema das ditaduras para segundo plano e em outros, como na prisão do general Augusto Pinochet ou na divulgação das supostas fotos de Herzog, tornase um dos principais pontos da agenda política do país.

Como um todo, a coletânea emociona. Rompe as paredes frias dos arquivos. Descreve experiências pessoais. Traz o depoimento de pessoas envolvidas na defesa da memória nacional e dos direitos humanos. Faz pensar sobre o direito que todos temos à informação sobre o passado recente desses países. Coloca-nos à frente de outros arquivos, divulgando para os pesquisadores possíveis fontes de trabalho. Apresenta múltiplos olhares. Aproxima-nos de nossos vizinhos demonstrando que não somos tão diferentes quanto imaginamos.

Ainda sem tradução para o português, a série tem sido doada para bibliotecas de Universidades e organizaçóes de direitos humanos no Brasil com o intuito de divulgar o trabalho, aproximar pesquisadores e estabelecer redes de pesquisas e solidariedade, rompendo o distanciamento entre o Brasil e os países vizinhos, que tem sido paulatinamente quebrado com o incentivo, 
212 - Samantha Viz Quadrat

oficial ou não, de projetos conjuntos. Que esta série seja só o início de pesquisas comuns! 